\title{
Predictors of presence, multiplicity, size and dysplasia of colorectal adenomas. A necropsy study in New Zealand
}

\author{
J R Jass, P J Young, E M Robinson
}

Abstract

Three hundred and thirty six forensic necropsy specimens of large bowel were examined in order to identify subject related variables that independently predicted the following adenoma characteristics: presence, size (largest), multiplicity and high grade dysplasia. The variables were age, gender, body mass index, race (European origin versus Maori Polynesian) and presence of hyperplastic (metaplastic) polyp(s). Subjects included 303 New Zealanders of European origin $(M=185$, $F=118$ ) yielding 149 adenomas and 251 hyperplastic polyps and 33 Maori/Polynesians $(M=25, F=8)$ yielding five adenomas and one hyperplastic polyp. Independent predictors of adenoma presence as determined by regression analysis were age $(p=0.0001)$, presence of hyperplastic polyps $(p=0.0001)$ and male gender $(p=0.05)$. Models were poor at explaining variation in size, multiplicity, and dysplasia. Larger adenomas occurred more frequently in subjects with multiple adenomas $(p=0.03)$ and multiple adenomas were probably associated with hyperplastic polyps $(p=0.09)$ and male gender $(p=0.09)$ in Europeans. High grade dysplasia was more frequent in women $(p=0.05)$ and possibly in subjects with hyperplastic polyps $(p=0 \cdot 2)$. Body mass index and ethnicity did not predict any adenoma characteristics, but hyperplastic polyp prevalence was influenced by European origin $(p=0.04)$ and to a lesser extent by body mass index $(p=0.08)$ as well as presence of adenoma $(p=0.0002)$ and age $(=0.005)$. The association of hyperplastic polyp with presence, multiplicity but not size of adenoma and with a high risk group for colorectal cancer (New Zealanders of European origin) suggests that the hyperplastic polyp serves as a marker for a factor which influences neoplastic evolution at the stages of initiation/transformation but not promotion. Fifty nine per cent of individuals with adenoma(s) did not have hyperplastic polyp(s), emphasising that the last would serve only as a marker of populations and not individuals at high risk of bowel cancer. Low intracolonic butyrate may be the factor linking the expression of the two types of polyp. (Gut 1992; 33: 1508-1514)

It is generally accepted that the majority of adenocarcinomas of the large bowel arise in pre existing adenomas. ${ }^{12}$ Necropsy studies provide an opportunity to ascertain baseline data concerning the distribution of adenomas in a particular group of patients or populations at differing risk of bowel cancer. ${ }^{3-12}$ Nevertheless, necropsy studies have been few and many have been unsatisfactory. Early reports did not distinguish clearly between adenomas and hyperplastic polyps, ${ }^{13-15}$ yet continue to be cited in contemporary reviews. ${ }^{16}$ Considerable interobserver variation in histological diagnosis is described in a major multicentre study. ${ }^{7}$ In one survey, most small rectal polyps were assumed to be hyperplastic, without histological verification. ${ }^{\circ}$ It is often impossible to determine if marked interstudy differences are genuine or the result of nonstandardised techniques. Finally, hospital necropsy series are highly selected and weighted towards an elderly population.

Although some necropsy studies have recorded the distribution of particular adenoma characteristics such as size and multiplicity, there has been little or no attempt to identify predictors of these features. Not only are size and multiplicity related to malignant risk, but they may be associated with factors implicated in the aetiology of bowel cancer. Thus multiplicity may reflect background level of mutagenic activity, whereas size may be influenced by the presence of growth promoting factors, while the ability to produce adenomas at all may be determined by genetic constitution."

The aim of this study was to determine the profile of variables linked independently to colorectal adenoma frequency, multiplicity and size in a forensic necropsy series. The variables were age, sex, race (European versus Maori and Polynesian), obesity and presence of hyperplastic (metaplastic) polyps. Through this approach it may be possible to derive some indication of the stage at which individual aetiological factors act in the evolution of the adenoma-carcinoma sequence.

\section{Methods}

\section{SPECIMENS}

Specimens of colon and rectum were obtained during forensic post mortem examinations conducted at Auckland University Medical School. Forensic necropsies afford a less selected sample than hospital necropsies, although deaths in subjects over 40 years were mainly because of natural causes. Patients with a history of abdominal surgery were excluded. The collection period (three years) was protracted in order to obtain a reasonable number of specimens from all age groups. When 30 specimens had accumulated for a particular decade and sex group, collection ceased for that group.

All specimens were carefully dissected down to 
the pelvic floor and the flexures were tied. The bowel was examined in a fresh state and in a well illuminated fume extractor by a single observer. The position of each polyp was marked on a map. All polyps were removed for routine histological examination to determine type and grade using World Health Organisation (WHO) approved criteria. ${ }^{18}$ The bowel was returned to the body. Polyps were measured in the fixed state before blocking.

Data were collated into two sets. The first data set related to information concerning each polyp. Polyps were histologically classified as tubular adenoma, tubulovillous adenoma, villous adenoma, hyperplastic (metaplastic) polyp, unclassified (autolysed) polyp, and other polyps, which were neither adenomas nor hyperplastic polyps. Each adenoma was given a histological grade (mild, moderate or severe) according to the WHO grading system for epithelial dysplasia. ${ }^{18}$ The location of each polyp was reported as being in the ascending colon, the transverse colon, the descending colon, the sigmoid colon and the rectum. The size $(\mathrm{mm})$ and the presence or absence of hyperplastic polyps was noted. The sex, age, and race of the patient harbouring each polyp was also recorded.

The second data set related to patient based factors. Each patient's age, sex, race, weight $(\mathrm{kg})$, and height $(\mathrm{m})$ was recorded as well as the number of adenomas, the number of hyperplastic polyps and the size of the largest adenoma in each subject. Body mass index was then calculated from weight $(\mathrm{kg}) /$ height $(\mathrm{m})^{2}$. This provides an index of obesity. ${ }^{19}$

Statistical Analysis System (SAS) programming language was used and the main functions used for analysing the data were frequency tables, $\chi^{2}$ tables, linear and logistic regression. The regression models were used to study the joint effect of a number of different factors on an outcome variable. Models are an attempt to provide an empirical summary of observed data

TABLE I Distribution of adenomas in male and female caucasians

\begin{tabular}{|c|c|c|c|c|c|c|}
\hline \multirow[b]{2}{*}{$\begin{array}{l}\text { Age } \\
(y r)\end{array}$} & \multicolumn{3}{|l|}{ Male } & \multicolumn{3}{|l|}{ Female } \\
\hline & $\begin{array}{l}\text { Specimens } \\
(n)\end{array}$ & $\begin{array}{l}\text { Adenoma }(s) \\
\text { present }\end{array}$ & $(\%)$ & $\begin{array}{l}\text { Specimens } \\
(n)\end{array}$ & $\begin{array}{l}\text { Adenoma }(s) \\
\text { present }\end{array}$ & $(\%)$ \\
\hline $10-19$ & 5 & 0 & (0) & 1 & 0 & $(0)$ \\
\hline $20-29$ & 30 & 0 & (0) & 12 & 0 & $(0)$ \\
\hline $30-39$ & 23 & 2 & (9) & 6 & 0 & $(0)$ \\
\hline $40-49$ & 20 & 2 & (10) & 7 & 1 & (14) \\
\hline $50-59$ & 30 & 12 & $(40)$ & 12 & 2 & (17) \\
\hline $60-69$ & 30 & 10 & (33) & 20 & 5 & (25) \\
\hline $70-79$ & 30 & 12 & (40) & 30 & 9 & (30) \\
\hline $80+$ & 17 & 9 & (53) & 30 & 8 & (27) \\
\hline Total & 185 & 47 & & 118 & 25 & \\
\hline
\end{tabular}

TABLE II Distribution of hyperplastic polyps in male and female caucasians

\begin{tabular}{|c|c|c|c|c|c|c|}
\hline \multirow[b]{2}{*}{$\begin{array}{l}\text { Age } \\
(y r)\end{array}$} & \multicolumn{3}{|l|}{ Male } & \multicolumn{3}{|l|}{ Female } \\
\hline & $\begin{array}{l}\text { Specimens } \\
(n)\end{array}$ & $\begin{array}{l}H P(s) \\
\text { present }\end{array}$ & $(\%)$ & $\begin{array}{l}\text { Specimens } \\
(n)\end{array}$ & $\begin{array}{l}H P(s) \\
\text { present }\end{array}$ & $(\%)$ \\
\hline $10-19$ & 5 & 0 & $(0)$ & 1 & 0 & (0) \\
\hline 20-29 & 30 & 0 & (0) & 12 & 0 & (0) \\
\hline $30-39$ & 23 & 0 & $(0)$ & 6 & 0 & (0) \\
\hline $40-49$ & 20 & 5 & (25) & 7 & 1 & (14) \\
\hline $50-59$ & 30 & 9 & (30) & 12 & 4 & (33) \\
\hline $60-69$ & 30 & 10 & (33) & 20 & 7 & (35) \\
\hline $70-79$ & 30 & 10 & (33) & 30 & 6 & (20) \\
\hline $80+$ & 17 & 6 & (35) & 30 & 4 & (13) \\
\hline Total & 185 & 40 & & 118 & 22 & \\
\hline
\end{tabular}

and do not imply a causal connection. Multiple linear regression models attempt to relate the response variable to more than one explanatory (independent) variable and the outcome variable is assumed to have a normal distribution. When there is a binary or ordinal outcome, linear regression is not appropriate and logistic regression is used in which the relationship between the probability of the outcome variable and the explanatory variables is investigated.

\section{Results}

The analysis involved 336 patients. Not all age groups had accumulated 30 patients, notably the young female age groups (Tables I, II). There were 303 caucasians ( 185 men, 118 women) and 33 Maori or Polynesians ( 25 men, eight women). The total yield of 495 polyps is grouped by type and race in Table III. Of the 154 adenomas, 149 were tubular, four were tubulovillous and one was villous. There were five flat adenomas which presented as slightly raised, well circumscribed plaques (Table IV). There were two adenocarcinomas, one a Dukes's B tumour arising in the hepatic flexure in a 92 year old woman and the other an advanced cancer with hepatic metastases arising in the sigmoid colon of an 89 year old woman.

Because all but five adenomas and one hyperplastic polyp came from caucasians and the sample size of Maori and Polynesians was small, the use of race as a factor was removed from some analyses.

\section{ANALYSIS OF ANATOMICAL DISTRIBUTION}

The anatomical distribution of the three major categories of polyp is given in Table V. Adenomas were distributed relatively evenly in the large bowel, whereas hyperplastic polyps

TABLE III Distribution of polyps by type and race

\begin{tabular}{llll}
\hline Type & European & $\begin{array}{l}\text { Maoriand } \\
\text { Polynesian }\end{array}$ & Total \\
\hline Adenoma & 149 & 5 & 154 \\
Hyperplastic & 251 & 1 & 252 \\
Unclassified & 74 & 0 & 74 \\
Other & 15 & 0 & 15 \\
& & & 495
\end{tabular}

TABLE IV Features of flat adenomas occurring in five subjects

\begin{tabular}{lllrll}
\hline Age & Gender & Site & $\begin{array}{c}\text { Size } \\
(\mathrm{mm})\end{array}$ & Type & Grade \\
\hline 78 & F & AC & 20 & TA & Moderate \\
78 & F & AC & 8 & TA & Mild \\
94 & F & AC & 40 & TV & Moderate \\
95 & F & AC & 7 & TA & Mild \\
78 & M & DC & 7 & TA & Severe \\
\hline
\end{tabular}

$\mathrm{AC}=$ ascending colon; $\mathrm{TA}=$ tubular adenomas $\mathrm{TV}=$ tubulovillous adenomas.

TABLE V Distribution of polyps by type and site

\begin{tabular}{lrrrrl}
\hline Type & $A C$ & $I C$ & $D C$ & $S C$ & $R$ \\
\hline Adenoma & $25 \%$ & $14 \%$ & $18 \%$ & $27 \%$ & $16 \%$ \\
Hyperplastic & $5 \%$ & $3 \%$ & $4 \%$ & $12 \%$ & $76 \%$ \\
Unclassified & $14 \%$ & $7 \%$ & $7 \%$ & $20 \%$ & $52 \%$ \\
\hline
\end{tabular}

$\mathrm{AC}=$ ascending colon $\mathrm{TC}=$ transverse colon $; \mathrm{DC}=$ descending colon; $\mathrm{SC}=$ sigmoid colon; $\mathrm{R}=$ rectum 
were found predominantly in the sigmoid colon and rectum ( $88 \%$ collectively). The unclassified polyps had a distribution more similar to that of hyperplastic polyps than adenomas, suggesting that the majority of the unclassified polyps were autolysed hyperplastic polyps.

Although the data in Table VI show more adenomas in the ascending and transverse colon $(49 \%)$ in women than men $(36 \%)$, the difference is not significant. In view of the older age of women harbouring adenomas in this study, a logistic regression analysis was used to determine the factor influencing the site of the adenomas. Site of adenoma (categorised as proximal colon (ascending colon + transverse colon + descending colon) and distal colon (sigmoid colon + rectum)) was used as the dependent variable with age and gender as the independent variables. The sample size was 154 . Only age $(p=0.007)$ was found to be significantly related to the site distribution for adenomas. This means that the difference in the site distribution between men and women seen in Table VI is probably because of the effect of the older female population.

Only $2 \%$ of hyperplastic polyps occurred proximal to the sigmoid colon in men, compared with $26 \%$ in the female sample (Table VII). The site of an adenoma was found to influence the size to which it grew (Table VIII). It was found that adenomas attained a larger size in ascending colon, sigmoid colon, and rectum. There was no relationship between the site of the adenoma and the presence or absence of coexisting hyperplastic polyps $(p=0.5)$ in a subject.

\section{SIZE AND GRADE OF POLYPS}

Each adenoma was grouped by size as $<5 \mathrm{~mm}$, $5-10 \mathrm{~mm}$, and $>10 \mathrm{~mm}$. There was no signifi-

TABLE VI Distribution of adenomas by site and gender

\begin{tabular}{llllll}
\hline Gender & $A C$ & $T C$ & $D C$ & $S C$ & $R$ \\
\hline $\mathrm{M}$ & $23 \%$ & $12 \%$ & $19 \%$ & $29 \%$ & $17 \%$ \\
$\mathrm{~F}$ & $31 \%$ & $18 \%$ & $13 \%$ & $23 \%$ & $15 \%$ \\
\hline
\end{tabular}

TABLE VII Distribution of hyperplastic polyps by site and gender

\begin{tabular}{lllcll}
\hline Gender & $A C$ & $T C$ & $D C$ & $S C$ & $R$ \\
\hline M & 1 & 1 & 1 & 11 & 86 \\
F & 4 & 11 & 10 & 16 & 58
\end{tabular}

AC, TC and DC $v$ SC and $\mathrm{R}, \chi^{2}=33.7(\mathrm{df}=1), \mathrm{p}<0.001$

TABLE VIII Influence of site upon size of adenomas

\begin{tabular}{llll}
\hline Size $(\mathrm{mm})$ & $\begin{array}{l}A C, \\
n o(\%)\end{array}$ & $\begin{array}{l}T C+D C, \\
n o(\%)\end{array}$ & $\begin{array}{l}S C+R, \\
n o(\%)\end{array}$ \\
\hline$<5$ & $11(28)$ & $26(55)$ & $21(33)$ \\
$5-10$ & $19(49)$ & $19(40)$ & $26(41)$ \\
$>10$ & $9(23)$ & $2(4)$ & $16(25)$ \\
\hline
\end{tabular}

TABLE IX Grade of adenomas and gender

\begin{tabular}{lll}
\hline Gender & $\begin{array}{l}\text { Low } \\
\text { grade }\end{array}$ & $\begin{array}{l}\text { High } \\
\text { grade }\end{array}$ \\
\hline M & 98 & 15 \\
F & 25 & 11 \\
\hline
\end{tabular}

\begin{tabular}{llcl}
\hline Age $(y r)$ & $l A D$ & $2 A D$ & $3+A D$ \\
\hline$<60$ & 15 & 2 & 5 \\
$60-79$ & 18 & 12 & 7 \\
$80+$ & 12 & 1 & 4 \\
\hline
\end{tabular}

cant difference between men and women when comparing these size groups $(p=0 \cdot 2)$. The size of the subject's largest adenoma was grouped similarly. Again, there was no significant gender difference. The size of each hyperplastic polyps was coded into size groups of $<5 \mathrm{~mm}, 5-10 \mathrm{~mm}$, and $>10 \mathrm{~mm}$. There was a significant difference between the size of hyperplastic polyps in men and women $(p=0.002)$, the largest occurring in women. To investigate factors influencing the size of hyperplastic polyps, a logistic regression analysis was used, with the size of hyperplastic polyps (categorised as above) as the dependent variable and age, gender and body mass index as the independent variables. Race was removed from the analysis as there was only one hyperplastic polyp from Maori/Polynesian specimens. Subjects without hyperplastic polyps were removed from the analysis. Gender $(p=0.02)$ and, to a less significant degree, body mass index $(p=0.07)$ were found to have an influence on the size of hyperplastic polyps. This means that women are more likely to get larger hyperplastic polyps and being overweight also increases this probability.

Adenoma grade was collapsed into two groups, low grade (mild dysplasia) and high grade (moderate and severe dysplasia) (Table IX). In order to investigate factors influencing the grade of adenomas in Europeans, a logistic regression was used, with low grade versus high grade as the dependent variable and age, sex, hyperplastic polyp and body mass index as the independent variables. Only gender $(p=0.05)$ made a significant contribution to the prediction of grade of adenomas, with women having a greater percentage of high grade adenomas. Hyperplastic polyps revealed a trend towards predicting high grade dysplasia $(p=0 \cdot 2)$.

\section{MULTIPLICITY OF ADENOMAS AND AGE}

Patients were grouped as less than 60,60-79 and $80+$ years of age. Although individuals aged 60 79 tended to show evidence of multiplicity, this trend did not continue with the $80+$ group and the overall differences were not significant (Table $\mathrm{X})$.

\section{INFLUENCE OF PATIENT DETERMINED VARIABLES} UPON ADENOMAS

Regression analysis was used to investigate the effect of subject determined variables (age, presence of hyperplastic polyps, race, body mass index, gender) on the formation of adenomas, namely their presence, multiplicity, and size. In order to investigate factors influencing the presence of an adenoma, a logistic regression was performed with the presence of one or more adenomas as the dependent factor and age, sex, race, hyperplastic polyps and body mass index as the independent variables. The sample size was the total of 336 subjects. Age $(p=0.0001)$, presence of hyperplastic polyps $(p=0.0001)$ and male gender $(p=0.05)$ made a significant contribution to explaining the presence of adenomas.

To determine factors influencing the formation of multiple adenomas logistic regression 
analysis was used with the number of adenomas per subject (one, two and three plus) as the dependent factor and age, sex, body mass index and the presence of hyperplastic polyps as the independent variables. The sample size was 72 as only Europeans were included in the analysis. The presence of hyperplastic polyps $(\mathrm{p}=0.09)$ and the gender of the subject $(p=0.09)$ had a relatively significant effect on the number of adenomas, meaning that if the subject was male and had at least one hyperplastic polyp, there was an increased probability of multiple adenomas.

In seeking factors influencing the size of the largest adenoma, a linear regression was used, with the size of the largest adenoma as the dependent variable and age, sex, race, body mass index, presence of hyperplastic polyps and the number of adenomas as the independent variables. The total sample was 76 , as subjects without adenomas were removed. The number of adenomas per subject $(p=0.03)$ was found to influence the size of the largest adenoma. The direction of the difference was that the greater the number of adenomas within an individual, the more likely they were to have a large adenoma. Hyperplastic polyps showed no association with adenoma size $(\mathrm{p}=0.9)$.

\section{INFLUENCE OF PATIENT DETERMINED VARIABLES} UPON HYPERPLASTIC POLYPS

To predict factors influencing the presence of hyperplastic polyps, a logistic regression was used, with the presence of hyperplastic polyps as the dependent variable and age, sex, race, presence of adenomas and body mass index as the independent variables. The sample size was 336. Presence of adenomas $(p=0.0002)$, age $(p=0.005)$, race $(p=0.04)$, and to a lesser degree body mass index $(p=0.08)$ were shown to make a significant contribution to predicting the presence of hyperplastic polyps. Thus older, overweight caucasians harbouring adenomas were more likely to have hyperplastic polyps.

A logistic regression was used to determine factors which influenced the formation of multiple hyperplastic polyps. The number of hyperplastic polyps per person was grouped as 1$5,6-10$, and $10+$ and these groups were used as the dependent variable, with age, sex, race, and body mass index as the independent variables. The sample size was 65 as all those without hyperplastic polyps were removed from the analysis. Age, sex, race, and body mass index were found to have no significant effect on the formation of multiple polyps.

\section{Discussion}

The ratio of yield of adenomas to hyperplastic polyps $(1: 1.6)$ is the resultant of the roughly similar 'prevalence' (Table I, II) and increased tendency to multiplicity for hyperplastic polyps. The view that hyperplastic polyps outnumber adenomas by a factor of $10: 1,{ }^{20}$ must now be regarded as a distorted impression based on data derived from surgical material obtained before the era of flexible endoscopy. In addition, the very large numbers of hyperplastic polyps seen commonly in the mucosa surrounding rectal cancers $^{21}$ are rarely seen in autopsy specimens, suggesting that rectal carcinoma may predispose to the development of hyperplastic polyps. It is, however, difficult to explain the varying adenoma to hyperplastic polyp ratios in different autopsy studies. Surveys from Hawaii, ${ }^{+} \mathrm{New}$ Jersey, ${ }^{5}$ and England 6 show up to a three-fold excess of hyperplastic polyps over adenomas, whereas a ratio close to unity is seen for Finland and Aberdeen $^{8}$ while adenomas outnumbered hyperplastic polyps in autopsy surveys from Colombia, ${ }^{3}$ Hong Kong, ${ }^{9}$ Norway, ${ }^{78}$ Mexico $^{12}$ and among the Maoris and Polynesians in the present study. It would seem that a low hyperplastic polyp to adenoma ratio characterises populations at low risk of bowel cancer, indicating that the hyperplastic polyp is a better marker for high risk populations than adenoma.

The majority of adenomas were tubular $(97 \%)$, mildly dysplastic (83\%) (Table IX) and less than $10 \mathrm{~mm}$ in diameter (83\%) (Table VIII), in keeping with previous post mortem reports. This agrees with the view that only a small proportion of adenomas evolve to malignancy. Flat adenomas mainly occurred in the right colon in elderly women (Table IV). Three of five showed high grade epithelial dysplasia, supporting the suggestion that these lesions have an increased propensity for malignant conversion. ${ }^{22-24}$ Their occurrence among very elderly subjects, however, raises some doubts about their colonoscopic importance. Flat adenomas have not been described previously in necropsy surveys. Adenomas were distributed relatively evenly throughout the colon (Table V). While there was a small excess in the proximal colon and distal colon, the distribution does not explain the relatively low incidence of cancer of the transverse and descending colon. In the ascending colon, descending colon and rectum, however, adenomas were more likely to exceed a diameter of $1 \mathrm{~cm}(\mathrm{p}=0.01)$, a finding noted previously..$^{568}$ The predilection for the right colon in women was entirely the result of the excess of elderly women in the series (Table VI). The influence of increasing age on the development of right sided adenomas is in accord with most, ${ }^{711}$ but not all ${ }^{6}$ earlier reports and fits well with the excess of right sided cancers in the elderly. ${ }^{25}$

A slightly greater proportion of adenomas $(23 \%)$ in women exceeded a diameter of $1 \mathrm{~cm}$ as compared with men (17\%), but this was not significant. In addition there was no difference in the size of the largest adenoma in men and women. In previous studies, adenomas have been described as larger in women, ${ }^{7}$ smaller $^{8}$ or the same as in men, ${ }^{26}$ but significant differences have not been shown. Adenomas in women, however, showed high grade dysplasia (31\%) more frequently than in men $(13 \%)(p=0.05)$. This effect was independent of age. A necropsy study $^{7}$ and a sigmoidoscopic survey from Norway $^{26}$ also noted the tendency for adenomas to be more dysplastic in women but this finding was not seen in the National Polyp study. ${ }^{27}$ The last describes a highly selected population, however, which greatly diminishes its epidemiological value. Given the lower prevalence of adenomas in women (Table I), but the roughly similar incidence of cancer in men and women, it must 
follow that adenomas in women have a higher malignant conversion rate and would therefore be expected to show more severe dysplasia.

Factors associated with the occurrence of adenomas in the necropsy survey were age, presence of hyperplastic polyps and male gender but not ethnicity or body mass index. The age effect $^{3+6-10}$ and association with men $^{5-810}$ is well known. The gradually increasing prevalence beyond the age of 50, however, does not match the exponential increase in the incidence of bowel cancer itself with age. Thus the steps involved in the generation of adenomas are few and some may be inherited, whereas time is a more critical factor in the multiple stepwise evolution of cancer. It is notable that a logistic regression analysis of a retrospective colonoscopic series also identified age, hyperplastic polyps and male gender as predictors of adenoma presence. ${ }^{28}$

The lack of an association with adenoma presence and ethnicity is of interest given the lower incidence of bowel cancer among Maori and Polynesians. ${ }^{29}$ Although the number of Maori and Polynesians specimens is small, logistic regression analysis is highly sensitive to differences among small samples. Other necropsy studies have also reported on a similar prevalence of adenomas among populations at differing risk of developing bowel cancer, ${ }^{79}$ although the general trend is for adenoma frequency to be correlated with bowel cancer incidence. ${ }^{48}$ The overall findings indicate that factors implicated in the evolution of adenoma and carcinoma overlap, but are not identical. Thus factors operating in particular sites within the large bowel and within populations at high risk of bowel cancer must serve to transform adenoma to carcinoma, yet are not required for the generation of adenomas.

The regression analysis to determine factors associated with adenoma size excluded gender, age, ethnicity, and body mass index, but showed the presence of multiple adenomas to be a predictor. This was also noted in the National Polyp Survey. ${ }^{27}$ Overall, the model was poor at explaining adenoma size, indicating the involvement of other factors, either hereditary or environmental, in adenoma growth.

This study showed no statistically significant relationship with multiplicity of adenomas and age (Table $\mathrm{X}$ ). Although more individuals aged 60-79 years had two or more adenomas than those younger than 60 , this trend did not continue with the $80+$ age group. Although earlier necropsy studies have described a relationship between multiplicity of adenomas and age,${ }^{+711}$ data have not been previously subjected to statistical analysis. While the lack of a significant result may reflect insufficient numbers, the negative finding is of interest. Thus, if each adenoma represents a focus of initiation caused by an environmental mutagen, a very clear relationship would be expected between multiplicity and age. The fact that this is not the case raises the possibility of an important confounding factor, such as a genetic predisposition to the development of multiple adenomas. Indeed, there is evidence that adenomas occurring apart from the syndrome of familial adenomatous polyposis may develop on the basis of a constitutional ten- dency. ${ }^{17}$ Logistic regression analysis showed the lack of an association between multiplicity and body mass index and ethnicity as well as age, but indicated hyperplastic polyps $(p=0.09)$ and gender $(p=0.09)$ as probable predictors of multiplicity in Europeans. Thus men with at least one hyperplastic polyp were more likely to have multiple adenomas.

Previous necropsy studies have shown the tendency of adenomas and hyperplastic polyps to occur within the same specimen, although this has not been analysed in detail. In one multicentre survey, subjects with adenomas were $3 \cdot 5$ times more likely to have a hyperplastic polyp as those without. ${ }^{8}$ Others found only a slight association and dismissed this as an age effect. ${ }^{6}$ In the last study, however, only 168 of 574 alleged hyperplastic polyps were diagnosed histologically. It is in colonoscopically derived material that the association between hyperplastic polyps and adenomas has been highlighted and the value of distal hyperplastic polyps as markers for proximal adenomas explored. ${ }^{28} 3031$

The percentage of adenoma positive specimens among hyperplastic polyp positive $(47 \cdot 7 \%)$ and hyperplastic polyp negative $(16.8 \%)$ specimens is remarkably similar to two colonoscopic surveys, ${ }^{2831}$ although differs somewhat from a third. ${ }^{30} \mathrm{~A}$ prospective colonoscopic survey that specifically addresses the role of distal hyperplastic polyps as markers for proximal adenomas does not find the hyperplastic polyp to be a clinically useful predictor. ${ }^{32}$ The last study, however, does not contradict the significant coexpression of the two lesions. Of further interest is the tendency for metachronous adenomas to occur most frequently in patients with multiple adenomas and hyperplastic polyps. ${ }^{33}$

Although adenomas and hyperplastic polyps frequently occur together, they markedly differ in their distribution within the large bowel (Table V), in the clearer association between prevalence of adenoma with both age and male gender (Tables I, II) and in their prevalence ratios in various populations (see above).

Hyperplastic polyps rarely exceed $5 \mathrm{~mm}$ in diameter and are generally acknowledged to be non-neoplastic. The relationship with age for hyperplastic polyps was stressed in earlier necropsy reports, ${ }^{+3+}$ but larger and more recent surveys ${ }^{689}$ have not confirmed this finding, showing no clear age relationship in necropsy subjects from middle age onwards. One series showed hyperplastic polyp prevalence to increase with age in men but not women. ${ }^{7}$ The present study shows a steady prevalence beyond 50 years.

The histopathological characteristics of hyperplastic polyps are quite distinct from adenomas. The most notable distinguishing features of hyperplastic polyps are the crypt serration, lack of crypt branching and lack of nuclear elongation and stratification. ${ }^{18}$ Cell kinetic studies show that the turnover of hyperplastic epithelium is more slow than normal. ${ }^{35}$ Ultrastructural studies show features of cellular hypermaturation and senescence. ${ }^{35}$ 36 Both morphological and histochemical studies show a premature development of normal cell surface characteristics within the serrated crypt epithelium. These features include the development of a microvillous brush 
border, ${ }^{36}$ downward extension of a subepithelial collagen table, ${ }^{37}$ loss of IgA secretory activity, ${ }^{38}$ increased apical expression of carcinoembryonic antigen,,$^{39+0}$ and expansion of the columnar cell cytoplasm. Enzymatic studies indicate a switch from aerobic to anaerobic metabolism. ${ }^{+1+2}$ Finally, mucin histochemistry shows increased secretion of mucin by columnar cells, as well as modifications to the structure of sialic acid. ${ }^{40}$ Is it possible that a single agent could be responsible for modulating maturation and producing these various phenotypic changes?

In separate regression analysis, hyperplastic polyps were shown to be less prevalent in the Maori/Polynesian group $(p=0.04)$, to be predictors of adenoma presence $(p=0.0001)$ and multiplicity $(p=0.09)$, to display a trend towards predicting high grade dysplasia $(p=0 \cdot 2)$, but to show no relationship with adenoma size $(\mathrm{p}=0.9)$. Furthermore, comparative epidemiology (see above) indicates hyperplastic polyps to be an important marker for high risk populations for colorectal cancer (perhaps more so than adenoma). On the other hand $59 \%$ of patients with adenomas did not have hyperplastic polyps. The most likely explanation for this is that hyperplastic polyps are the result of two factors, only one of which is important in the process of neoplastic evolution. When this factor alone is present adenomas may occur in the absence of hyperplastic polyps. There is circumstantial evidence to suggest that the two factors are conditions causing focal mucosal injury and a diet that leads to low concentrations of butyrate within the large bowel.

The enzymatic changes (indicative of a switch from aerobic to anaerobic metabolism) and the distal location of hyperplastic polyps suggest the possibility of an underlying nutritional lack. Butyrate, formed normally by the fermentation of plant fibre and starch in the ascending colon is the main energy source for the colonocyte. ${ }^{43}$ Concentrations of this short chain fatty acid are lowest in the distal colon ${ }^{44}$ and this would be exacerbated in populations taking a low fibre diet. Hyperplastic polyps (and closely related mucosal alterations) occur in sites that are prone to mild ischaemia through prolapse, that is, the mucosa surrounding cancers, the middle third of the rectum, in association with the solitary rectal ulcer syndrome and on the crests of mucosal folds. ${ }^{45}$ Mild ischaemic damage may result in evanescent erosions that heal rapidly through epithelial regeneration. In the background of relative butyrate deficiency that is now coupled to an increased requirement for energy, hyperplastic epithelium appears to adapt by switching to anaerobic methods of metabolism. This may in turn block the use of a butyrate, which is then free to alter the cell's programmed pattern of differentiation. Butyrate is known to promote maturation and differentiation of malignant cells in vitro ${ }^{46}$ and will presumably act similarly on non-neoplastic proliferating cells that are unable to metabolise the chemical in the usual way. The overall result will be a hyperplasia followed by an early and exaggerated maturation, that is, exactly the picture that occurs in hyperplastic polyps.

In conclusion, the findings of the study indicate hyperplastic polyps to be a marker of an environmental factor that increases the rate of initiation/mutagenesis but does not influence promotion. This is based on the inference that presence and multiplicity of adenomas serve as signals of mutational events whereas size is an indicator of tumour promotion. Furthermore hyperplastic polyps serve as markers for high risk populations, but not individuals. The relation between hyperplastic polyps and adenomatous dysplasia is unclear and warrants further study. There are numerous hypotheses linking a low fibre diet and enhanced mutagenesis. It is possible also that low levels of butyrate might augment the conversion of adenomas to carcinoma by exerting selection pressures that would favour the emergence of more resilient clones.

This study could not have been undertaken without the considerable assistance of the Forensic Section of the Department of Pathology.

1 Muto T, Bussey HJR, Morson BC. The evolution of cancer of the rectum. Cancer 1975; 36: 2251-70.

2 Jass JR. Do all colorectal carcinomas arise in pre-existing adenomas? World 7 Surg 1989; 13: 45-51.

3 Correa P, Duque E, Cuello C, Haenszel W. Polyps of the colon and rectum in Cali, Colombia. Int $\mathcal{F}$ Cancer 1972; 9: 86-96. 4 Stemmermann GN, Yatani R. Diverticulosis and polyps of the large intestine. Cancer 1973; 31: 1260-70.

5 Rickert RR, Auerbach O, Garfinkel L, Hammond EC, Frasca JM. Adenomatous lesions of the large bowel. An autopsy survey. Cancer 1979; 43: 1847-57.

6 Williams AR, Balasooriya BAW, Day DW. Polyps and cancer of the large bowel: a necropsy study in Liverpool. Gut 1982; 23: $835-42$.

7 Vatn $\mathrm{MH}$, Stalsberg $\mathrm{H}$. The prevalence of polyps of the large intestine in Oslo: an autopsy study. Cancer 1982; 49: 819-25.

8 Clark JC, Collan Y, Eide TJ, Estève J, Ewen S, Gibbs NM, et al. Prevalence of polyps in an autopsy series from areas with varying incidence of large-bowel cancer. Int $\mathcal{F}$ Cancer with varying inciden

9 Coode PE, Chan KW, Chan YT. Polyps and diverticula on the large intestine - a necropsy survey in Hong Kong. Gut 1985; 26: $1045-8$

10 Passarino G, Mollo F. Colorectal adenomas in an Italian autopsy population. Ital $\mathcal{F}$ Gastroenterol 1986; 18: 197-200.

11 Johannsen LGK, Momsen O, Jacobsen NO. Polyps of the large intestins in Aarhus, Denmark. An autopsy study. Scand F Gastroenterol 1989; 24: 799-806.

12 Chavez-Macias LG, Jessurun J, Sanchez YNM. Prevalencia de pólipos adenomatosos e hiperplásicos del colon en la problación del Hospital General de México. Un estudio de autopsias. Rev Invest Clin 1990; 42: 193-7.

13 Blatt LJ. Polyps of the colon and rectum: incidence and distribution. Dis Colon Rectum 1961; 4: 277-82.

14 Chapman I. Adenomatous polyps of large intestine: incidence and distribution. Ann Surg 1963; 157: 223-6.

15 Arminski TC, McClean DW. Incidence and distribution of adenomatous polyps of the colon and rectum based on 1000 autopsy examinations. Dis Colon Rectum 1964: 7: 249-61.

16 Ransohoff DF, Lang CA. Screening for colorectal cancer. NEnglf Med 1991; 325: 37-41.

17 Burt RW, Bishop T, Cannon LA, Dowdle MA, Lee RG, Skolnick MH. Dominant inheritance of adenomatous colonic polyps and colorectal cancer. $N$ Engl f Med 1985; 312: $1540-4$.

18 Jass JR, Sobin LH. Histological typing of intestinal tumours: WHO International classification of tumours. Berlin: SpringerVerlag, 1989.

19 Bray GA. Definition, measurement and classification of the syndromes of obesity. Int $f$ Obesity 1978; 2: 99-112.

20 Fenoglio CM, Lane N. The anatomical precursor of colorectal carcinoma. Cancer 1974; 34: 819-23.

21 Eide TJ. Prevalence and morphological features of adenomas of the large intestine in individuals with and without colorectal carcinoma. Histopathology 1986; 10: 110-8.

22 Muto T, Kamiya J, Sawada T, Konishi F, Sugihara K, Kubota $\mathrm{Y}$, et al. Small 'flat adenoma' of the large bowel with special reference to its clinicopathologic features. Dis Colon Rectum 1985; 28: 847-51

23 Kuramoto S, Ihara O, Sakai S, Shimazu R, Kaminishi M, Oohara T. Depressed adenoma in the large intestine: endoscopic features. Dis Colon Rectum 1990; 33: 108-12.

24 Wolber RA, Owen DA. Flat adenomas of the colon. Hum Pathol 1991; 22: 70-4.

25 Jass JR. Subsite distribution and incidence of colorectal cancer in New Zealand. Dis Colon Rectum 1991; 34: 56-9.

26 Hoff G, Foerster MH, Vatn MH, Gjone E. Epidemiology of polyps in the rectum and sigmoid colon. Histological polyps in the rectum and sigmoid colon. Histological 20: 677-83.

27 O'Brien MJ, Winawar SJ, Graham Zauber A, Gottlieb LS, Sternberg SS, Diaz B, et al. The National Polyp Study. Patient and polyp characteristics associated with high grade dysplasia in colorectal adenomas. Gastroenterology 1990; 98: 
28 Naveau S, Brajer S, Bedossa P, Poynard T, Chaput J-C. Hyperplastic colonic polyps as a marker for adenomatous

9 Smith AH, Pearce NE, Joseph JG. Major colorectal cancer aetiological hypotheses do not explain mortality trends among Maori and Non-Maori New Zealanders. Int $f$ Epidemiol 1985; 14: 79-85.

30 Provenzale D, Martin ZZ, Holland KL, Sandler RS. Colon adenomas in patients with hyperplastic polyps. F Clin Gastroenterol 1988; 10: 46-9.

31 Ansher AF, Lewis JH, Fleischer DE, Cattau EL Jr, Collen MJ, O'Kieffe DA, et al. Hyperplastic colonic polyps as a marker for adenomatous colonic polyps. Am $\mathcal{F}$ Gastroentero 1989; 84: 113-7.

32 Provenzale D, Garrett JW, Condon SE, Sandler RS. Risk for colon adenomas in patient with rectosigmoid hyperplastic polyps. Ann Intern Med 1990; 113: 760-3.

33 Kellokumpu I, Kyllönen L. Multiple adenomas and synchronous hyperplastic polyps: predictors of metachronous colorectal adenomas. Ann Chir Gynaecol 1991; 80: 30-5.

34 Arthur JF. Structure and significance of metaplastic modules in the rectal mucosa. $\mathcal{F}$ Clin Pathol 1968; 21:735-43.

35 Hayashi T, Yatani R, Apostol J, Stemmermann GN. Pathogenesis of hyperplastic polyps of the colon: An hypothesis genesis of hyperplastic polyps of the colon: An hypothesis based on ultrastructure and

36 Kaye GE, Fenoglio CM, Pascal RR, Lane N. Comparative electron microscopic features of normal, hyperplastic and adenomatous human colonic epithelium. Gastroenterology $1974 ; 66: 347-56$.

37 Grondin MV, Chang WWL, Gaskins RD. Crypt alterations and collagen deposition in hyperplastic polyps of the colon. Dig Dis Sci 1990; 35: 12-9.

38 Jass JR, Faludy J. Immunohistochemical demonstration of IgA and secretory component in relation to epithelial cell differentiation in normal colorectal mucosa and metaplastic polyp. Histochem $\mathcal{F}$ 1985; 17: 373-80.

39 Gebbers J-O, Laissue JA. Mixed hyperplastic and neoplastic polyps of the colon. An immunohistological study. Vircholos polyps of the colon. An imn

40 Jass JR, Filipe MI, Abbas S, Falcon CAJ, Wilson Y, Lovell D A morphologic and histochemical study of metaplastic polyps of the colorectum. Cancer 1984; 53: 510-5.

41 Czernobilsky B, Tsou KC. Adenocarcinoma, adenomas and polyps of the colon. Cancer 1968;21: 165-77.

42 Wattenberg LW. A histochemical study of five oxidative enzymes in carcinoma of the large intestine in man. Am F Pathol 1959; 35: 113-26.

43 Roediger WEW. Anaerobic bacteria support the metabolic welfare of the colonic mucosa in man. Gut 1980; 21: 793-8.

44 Clausen MR, Bonnén $\mathrm{H}$, Mortense of dietary fibre to short chain fatty acids in patients with adenomatous polyps and colonic cancer. Gut 1991; 32:
923-8.

45 Franzin G, Dina R, Zamboni G, Iannucci A, Scarpa A, Novell P. Hyperplastic (metaplastic) polyps of the colon. A histological and histochemical study. Am $\mathcal{F}$ Surg Pathol 1984; 8 : 687-98

46 Augeron C, Laboisse CL. Emergence of permanently differentiated cell clones in a human colonic cancer cell line in culture after treatment with sodium butyrate. Cancer Res 1984; 44: 3961-9. 